\title{
Application of whey retentate as complex nitrogen source for growth of the polyhydroxyalkanoate producer Hydrogenophaga pseudoflava strain DSM1023
}

\author{
Martin Koller ${ }^{1,2, *}$, Paula Hesse ${ }^{3}$ and Gerhart Braunegg ${ }^{2}$
}

\begin{abstract}
Polyhydroxyalkanoates, microbial polyesters produced in vivo starting from renewable resources, are considered the future materials of choice to compete recalcitrant petro-chemical plastic on the polymer market. In order to make polyhydroxyalkanoates market-fit, (techno)economics of their production need to be improved. Among the multifarious factors affecting costs of polyhydroxyalkanoate production, increased volumetric productivity is of utmost importance. Improving microbial growth kinetics and increasing cell density are strategies leading to a high concentration of catalytically active biomass within a short time; after changing cultivation conditions, these cells can accumulate polyhydroxyalkanoates as intracellular products. The resulting increase of volumetric productivity for polyhydroxyalkanoates can be realized by supplying complex nitrogen sources to growing microbial cultures. In the present study, the impact of different expensive and inexpensive complex nitrogen sources, in particular whey retentate, on the growth and specific growth rates of Hydrogenophaga pseudoflava was tested.

Based on a detailed kinetic process analysis, the study demonstrates that especially whole (not hydrolyzed) whey retentate, an amply available surplus material from dairy industry, displays positive effects on cultivations of $H$. pseudoflava in defined media (increase of concentration of catalytically active biomass after $26.25 \mathrm{~h}$ of cultivation by about $50 \%$, increase of specific growth rate $\mu$ from 0.28 to $0.41 \mathrm{1} / \mathrm{h}$ during exponential growth), while inhibiting effects (inhibition constant $K_{i}=6.1 \mathrm{~g} / \mathrm{L}$ ) of acidically hydrolyzed whey retentate need to be overcome. Considering the huge amounts of surplus whey accruing especially in Europe, the combined utilization of whey permeate (carbon source) and whey retentate (complex nitrogen source) for biopolyester production can be considered a viable bioeconomic strategy for the next future.
\end{abstract}

Keywords: Bioeconomy, biopolyesters, biopolymers, complex nitrogen sources, feedstocks, growth additives, industrial waste, polyhydroxyalkanoates (PHA), whey, whey retentate

'University of Graz, Institute of Chemistry, NAWI Graz, Austria

${ }^{2}$ ARENA (Association for Resource Efficient and Sustainable Technologies), Graz, Austria

${ }^{3}$ Graz University of Technology, Institute of Biotechnology and Biochemical Engineering

*Corresponding author: M. Koller E-mail: martin.koller@uni-graz.at

DOI: 10.2478/ebtj-2019-0009

(C) 2019 Authors. This work was licensed under the Creative Commons AttributionNonCommercial-NoDerivs 4.0 License.

\section{Introduction}

Current literature makes as familiar with the tremendously aggravating global plastic situation, which is reflected by an enormous current annual production of highly recalcitrant plastics of petrochemical origin, which is approaching the tremendous quantity of $0.4 \mathrm{Gt}$. A possible way out of this predicament is switching to biologically produced, biodegradable polymeric materials with plastic-like properties (1); especially microbial polyhydroxyalkanoates (PHAs) are considered auspicious candidates to fulfill this task $(2,3)$. PHAs are biopolyesters accumulated by various prokaryotic organisms starting from renewable feedstocks; both heterotrophic and autotrophic PHA production is reported $(4,5)$. PHAs can be processed to plastic items by various techniques established in polymer industry, such as melt extrusion, injection molding, compression molding, wet spinning, electrospinning, or 3D-printing (6). Selected examples for PHA application involve (food) packaging (7) or the pharmaceutical and biomedical field (8). Among heterotrophic PHA producers, Gram-negative strains currently outperform their Gram-positive counterparts in terms of scientific reports and (semi)industrial application for PHA production $(9,10)$. 
Beside extremophilic Gram-negative PHA producers thriving in challenging hot, hyper-saline, alkaline, or heavy metal-contaminated habitats $(11,12)$, also various mesophilic bacteria are described as proficient PHA production factories. Among the myriad of investigated strains, especially those utilizing inexpensive feedstocks, growing fast, and accumulating high intracellular PHA fraction attract most attention for bio-economic industrial-scale PHA production $(4,5)$.

As an example for microbial strains accumulating significant quantities of PHAs, the yellow-pigmented betaproteobacterium Hydrogenophaga pseudoflava (formerly known as Pseudomonas pseudoflava before its taxonomic re-classification into Hydrogenophaga, a new genus of hydrogen-oxidizing bacteria, in 1989 (13)) was successfully tested on shaking flask scale as whole cell biocatalyst for synthesis of PHA from pure substrates like glucose, fructose (14), lactose and sucrose (15). This strain is also an expedient PHA producer when supplied with the lactose-rich permeate fraction of whey, an amply available surplus product of dairy industry. On bioreactor scale, the strain showed a preference for hydrolyzed whey permeate (mainly an equimolar mixture of glucose and galactose) if compared to the use of whole whey permeate (not hydrolyzed lactose) for production of the rather low-quality PHA homopolyester poly(3-hydroxybutyrate) (16,17). Moreover, the strain produces high-quality PHA copolyesters when supplied with precursor compounds structurally related to the PHA building blocks 3-hydroxyvalerate (3HV; used precursors: valeric acid (16), $\gamma$-valerolactone $(18,19)$, levulinic acid $(20))$ or 4-hydroxybutyrate (4HB; precursor: GBL $(18,19,21))$. Remarkably, $H$. pseudoflava is able to produce poly $(3 \mathrm{HB}-$ co- $4 \mathrm{HB})$ copolyesters with high fractions of $4 \mathrm{HB}$ monomers, which are not degraded intracellularly even under conditions of absence of exogenous carbon sources and abundant availability of nitrogen and phosphate source; for $4 \mathrm{HB}$ contents of $95 \mathrm{~mol}-\%$ and higher, these copolyesters are not accessible towards interactions with the strain's intracellular depolymerase enzymes (21). Later, these findings were substantiated by demonstrating that in intracellular blends of $\mathrm{PHB}$ and poly $(4 \mathrm{HB})$ homopolyesters, only $\mathrm{PHB}$ is degraded according to a first order kinetic, while poly $(4 \mathrm{HB})$ remains intact; for poly(3HB-co-4HB) copolyesters, intracellular degradability was only possible above a minimum $3 \mathrm{HB}$ fraction, evidencing the high substrate specificity of the depolymerases of $H$. pseudoflava, and the high impact of the polyester microstructure on degradability (19). When co-feeding $\gamma$-valerolactone and $\gamma$-butyrolactone, the strain produced poly $(3 \mathrm{HV}$ co-4HB) copolyesters, which constituted intracellular blends of $3 \mathrm{HV}$-rich and $4 \mathrm{HB}$-rich copolyester chains; in analogy to poly $(3 \mathrm{HB}-\mathrm{co}-4 \mathrm{HB})$ copolyesters, high $3 \mathrm{HV}$ fractions favored degradability in contrast to $4 \mathrm{HB}$. Moreover, poly(3HV-co$4 \mathrm{HB}$ ) with a $50 / 50$ ratio of $3 \mathrm{HV} / 4 \mathrm{HB}$ produced in this study turned out to be completely amorphous materials (22). Another intriguing aspect was more recently described by Povolo et al., who detected small amounts of $3 \mathrm{HV}$ in PHAs accumulated by this strain on sucrose or lactose as sole carbon sources; when adding yeast extract, even traces of $4 \mathrm{HB}$ were detected without any precursor compound, which was also the case when using whole whey plus yeast extract; the authors assumed that compounds present in whey and yeast extract might act as $3 \mathrm{HV}$ and $4 \mathrm{HV}$ precursor compounds for this strain (15).

However, achieved results for volumetric PHA productivity and intracellular PHA fraction for $H$. pseudoflava from labscale experiments are not yet competitive with the most widely used PHA production strain Cupriavidus necator (formerly known as Wautersia eutropha, Ralstonia eutropha, or Alcaligenes eutrophus (23)). In this context, it was of interest to study the possibility to enhance volumetric PHA productivity by reaching higher amounts of catalytically active biomass within a shorter time by adapting the composition of the nutrient broth during the phase of biomass growth; after switching the cultivation conditions (typically by provoking a limitation of a growth essential nutrient like nitrogen- or phosphate source), a higher total quantity of PHA can be produced per fermentation batch than in the case of low cell density (24). The present study was inspired by previous literature reports, which evidenced enhanced growth, especially reduced lag (adaptation) phase of growth and higher cell density, when adding complex nitrogen sources like yeast extract (25), fish peptone (26), casamino acids (27), or magnesium-rich pressed juices of fresh or fermented grass, which constitute a product from grass biorefinery processes $(28,29)$, to cultures of PHA accumulating microbes.

Regarding whey retentate, the successful use of enzymatically hydrolyzed whole whey as substrate in PHA production processes was reported some years ago for C. necator growing on plant oils as main carbon source by Obruca and colleagues; it was shown that additions of this growth additive enhanced PHA productivity from plant oils by a factor of 3-5 in shaking flask setups, and increased conversion yield of plant oils to PHA by about $40 \%$ (30). As an absolute novelty, the study at hand investigated the effect of adding whey lactose as complex nitrogen source to cultivations of $H$. pseudoflava on hydrolyzed whey permeate as carbon source on the growth kinetics and biomass formation of the strain.

Nota bene: Separation of whey into retentate and permeate allows providing the optimum $\mathrm{C} / \mathrm{N}$ ratio in both phases of the cultivation, while using whole whey displays several disadvantages: (i) Whey is too highly diluted (not suitable in fed-batch processes; would result in excessive volume increase in the bioreactor); (ii) no possibility to supply sufficient amounts of organic nitrogen source during growth phase (in comparison to carbon content), and no possibility to operate the system under nitrogen-free conditions in the second phase (PHA accumulation phase). Especially for future continuous cultivation processes (in particular when using at least two continuously operated bioreactors in series), a fine-tuned and independent continuous supply with nitrogen and carbon sources is indispensable.

The effect of adding whey retentate was compared with cultivation batches using ammonia sulfate as sole, inorganic nitrogen source, and with setups supplied with additional complex nitrogen sources, namely yeast extract, malt extract, meat ex- 


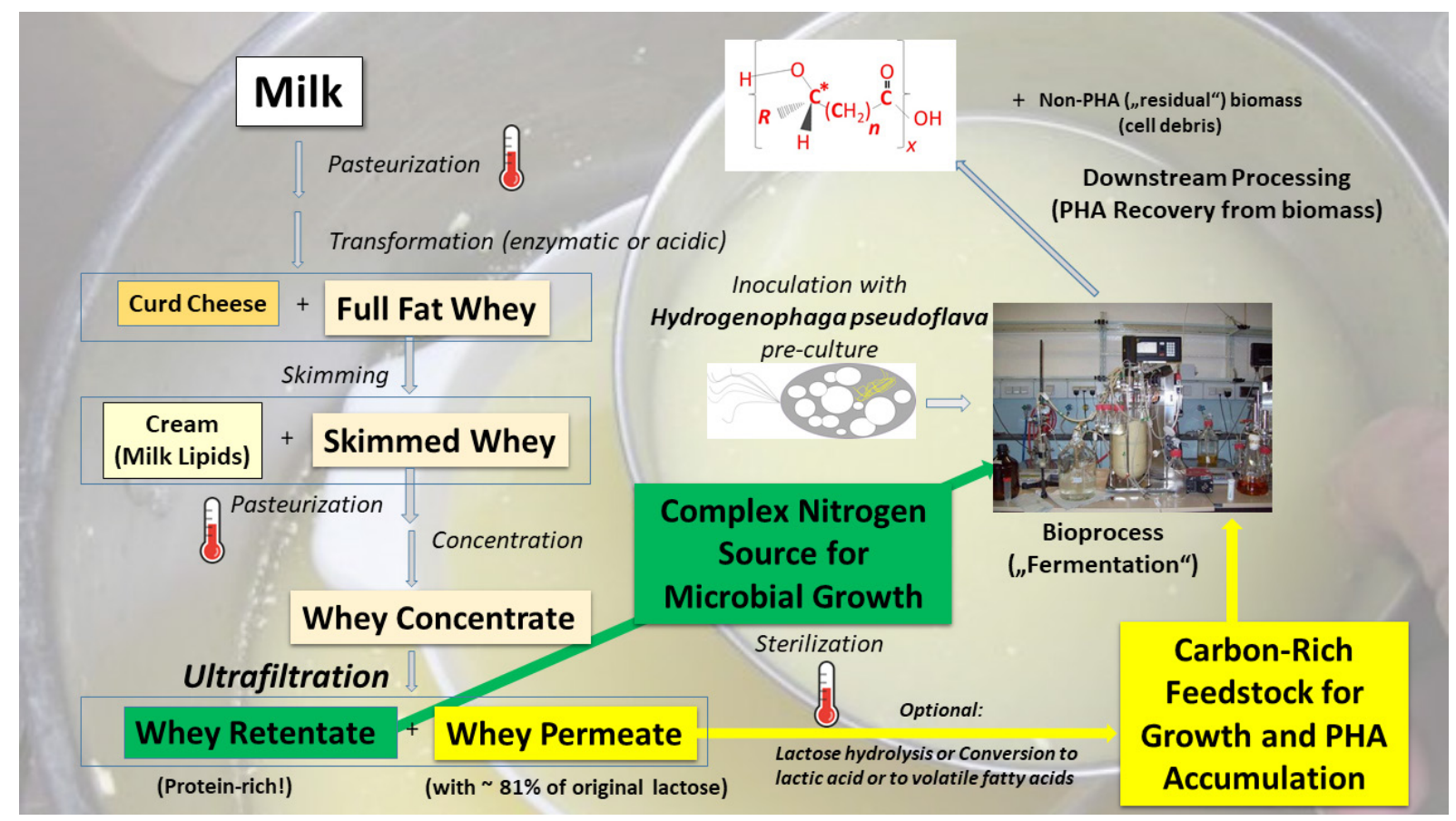

Figure 1. Processing of whey towards a feedstock for PHA production (based on (34)).

tract, corn steep liqueur (CSL), hydrolyzed casein, and pressed juice of grass silage. Whey retentate was particularly selected for this study to complement the excellent performance of the strain in producing PHAs from whey permeate as carbon source $(16,17)$; using both the permeate and the retentate fraction in a PHA production process would pave the way towards a complete utilization of the surplus material whey, which, due to its high (bio)chemical oxygen demand, currently poses environmental threats when disposed as waste into aquatic environments (29). In addition, this new application of whey retentate for PHA biosynthesis can be considered a complementary strategy to other value-added applications of this material in the bioplastic field, such as coating of films made of non-degradable petrochemical plastics to enhance oxygen barrier properties and reduce the plastic's ecological footprint (31), or to fine tune gas barrier properties of films made of other biode- gradable polymers (32). Fig. 1 visualizes the processing steps of whey towards a substrate for biotechnological PHA production, while Table 1 summarizes the chemical composition of different types of whey.

After this basic experiment, the application of different concentrations of whole whey retentate and acidically hydrolyzed whey retentate were compared in terms of impact on growth kinetics and biomass formation of $H$. hydrogenophaga.

\section{Materials and Methods}

Strain

Hydrogenophaga pseudoflava DSM 1034 (formerly known as Pseudomonas pseudoflava) was obtained from DSMZ culture collection (Braunschweig, Germany). Culture maintenance was done on solidified agar slants containing a mineral medium (H3) with the following composition $(\mathrm{g} / \mathrm{L}): \mathrm{NaHCO}_{3} 0.5$,

Table 1. Chemical composition of milk and different types of whey (based on (33))

\begin{tabular}{|c|c|c|c|c|c|c|c|}
\hline $\begin{array}{c}\text { Compound } \\
(\%(w / w))\end{array}$ & Milk & $\begin{array}{c}\text { Sweet } \\
\text { Whey }\end{array}$ & $\begin{array}{c}\text { Dry Sweet } \\
\text { whey } \\
\text { (powder) }\end{array}$ & $\begin{array}{c}\text { Fermented } \\
\text { whey } \\
\text { (powder) }\end{array}$ & $\begin{array}{c}\text { Dry sweet } \\
\text { whey } \\
\text { (powder) }\end{array}$ & $\begin{array}{c}\text { Whey } \\
\text { Permeate } \\
\text { (this study) }\end{array}$ \\
$\begin{array}{c}\text { Retentate } \\
\text { (this study) }\end{array}$ \\
\hline Lactose & ca. 4.8 & $4.7-4.9$ & 73.5 & $4.5-4.9$ & 65.6 & 23 & 14 \\
\hline Lactic acid & - & traces & traces & 0.5 & 7 & n.d. & n.d. \\
\hline Proteins & $3.4-3.5$ & $0.75-1.1$ & 12.9 & 0.45 & 12.3 & 0.75 & 13 \\
\hline Lipids & $>4.2$ & $0.15-0.2$ & 1.1 & traces & 1.0 & n.d. \\
\hline $\begin{array}{c}\text { Minerals (e.g., } \\
\text { calcium, phosphate) }\end{array}$ & $\sim 0.7$ & ca. 0.7 & 8 & $0.6-0.7$ & 11 & ca. 2.7 \\
\hline
\end{tabular}


$\mathrm{Na}_{2} \mathrm{HPO}_{4} 2.9, \mathrm{KH}_{2} \mathrm{PO}_{4} 2.3$, agar-agar $15, \mathrm{MgSO}_{4}{ }^{\star} 7 \mathrm{H}_{2} \mathrm{O} 0.5$, Ca$\mathrm{Cl}_{2}{ }_{2} \mathrm{H}_{2} \mathrm{O} 0.01, \mathrm{NH}_{4} \mathrm{Fe}(\mathrm{III})$ citrate 0.05 , trace element solution SL6 $5 \mathrm{~mL}$ (composition according to (27)), plus hydrolyzed whey permeate at a quantity resulting in a total sugar (glucose + galactose) concentration of $10 \mathrm{~g} / \mathrm{L}$.

\section{Cultivations}

\section{Preliminary testing of different complex nitrogen sources}

Hydrogenophaga pseudoflava was inoculated from single colonies taken from agar slants with minimal medium $\mathrm{H} 3$ to 50

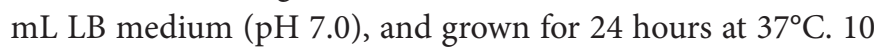
$\mathrm{mL}$ of this pre-culture was added to $250 \mathrm{~mL}$ of $\mathrm{H} 3$ medium in $1 \mathrm{~L}$ shaking flasks, containing $2 \mathrm{~g} / \mathrm{L}$ of the inorganic nitrogen source ammonium sulfate and hydrolyzed whey permeate at a quantity resulting in a total sugar concentration of $10 \mathrm{~g} / \mathrm{L}$; the $\mathrm{pH}$-value was adjusted to 7.0. Different complex nitrogen sources (yeast extract, malt extract, meat extract, CSL, hydrolyzed casein, silage juice, and whey retentate) were added to the individual setups at concentrations of $2 \mathrm{~g} / \mathrm{L}$ each, and compared with setups without complex nitrogen source; each experimental setup was carried out in duplicate. All shaking flasks were incubated on a rotary shaker at $37^{\circ} \mathrm{C}$ operated at $130 \mathrm{rpm}$ for 24 hours.

\section{Comparison of hydrolyzed and non-hydrolyzed whey reten- tate as complex nitrogen source}

Pre-culture: $100 \mathrm{~mL}$ of $\mathrm{H} 3$ containing hydrolyzed whey permeate (total sugar concentration $10 \mathrm{~g} / \mathrm{L}$ ) was inoculated with $5 \mathrm{~mL}$ of the LB cultures (vide supra). After 21 hours, when the cells had reached the late exponential phase, $14300 \mathrm{~mL}$ shaking flasks, each containing $100 \mathrm{~mL} \mathrm{H} 3$ medium, were inoculated with $4 \mathrm{~mL}$ inoculum culture. Two flasks, the references, contained ammonium sulfate as sole nitrogen source, whereas hydrolyzed or not hydrolyzed whey retentate at concentrations of $0.5,2$ and $5 \mathrm{~g} / \mathrm{L}$ were added to the other setups. All shaking flasks were incubated at $37^{\circ} \mathrm{C}$ with $130 \mathrm{rpm}$ for 24 hours. All experimental setups were done in duplicate. Sampling was done every three hours.

\section{Whey}

Sweet whey (composition see Table 1), a by-product of the Asiago DOC cheese production, was provided by the Italian dairy company Latterie Vincentine S.c.a., Italy (LAVI). Separation of whey into whey permeate and whey retentate was accomplished directly at LAVI via ultrafiltration. Lactose in whey permeate was hydrolyzed enzymatically by adding the enzyme formulation Maxilact LG 2000 ${ }^{\mathrm{TM}}$ (DSM Food Specialities, UK; $2.5 \mathrm{~mL}$ per $\mathrm{L}$ whey permeate) at a $\mathrm{pH}$ of $6.5-7$ and a temperature of $37^{\circ} \mathrm{C}$ and stirring for 24 hours according to a previously published protocol (35). The whey retentate fraction was subjected towards acidic hydrolysis by adding $6 \mathrm{M} \mathrm{HCl}(1 \mathrm{~mL}$ per $\mathrm{g}$ retentate) and continuous magnetic stirring at $90^{\circ} \mathrm{C}$ for 24 hours. After cooling and monitoring completeness of hydrolysis, the $\mathrm{pH}$-value of the hydrolysis cocktail was adjusted to 7.0 by adding an adequate quantity of aqueous $\mathrm{NaOH}$ solution.

\section{Optical density}

Microbial growth of $H$. pseudoflava was monitored during the experiments by measuring the optical density at a wavelength of $420 \mathrm{~nm}$ using a Spectronic genesys 2 PC UV/VIS spectrophotometer after each sampling; for each measurement, filtrated supernatant was used as zero-reference.

\section{Ammonium determination}

Ammonium was measured electrochemically with an ion-sensitive Orion electrode using ammonium sulfate standard solutions (30-3000 ppm) (27).

\section{Cell dry mass determination}

$5 \mathrm{~mL}$ of liquid sample broth was centrifuged $\left(4^{\circ} \mathrm{C}, 12,000 \mathrm{~g}\right.$; Megafuge 1.0R Hereus Sepatech) in pre-weighed glass tubes. The filtered supernatant was used for determination of carbon sources (glucose and galactose) and ammonium sulfate. The remaining pellet was frozen and lyophilized (freeze-drying apparatus Christ Alpha 1-4 B) until mass constancy. After weighing, the difference between tubes containing dry cell pellets and corresponding empty tube weights was defined as the cell dry mass $(\mathrm{CDM})$ in $5 \mathrm{~mL}$ fermentation broth.

\section{Determination of carbon sources}

The concentrations of glucose, galactose, and lactose were measured with an HPLC equipment consisting of a thermostated Aminex HPX 87H column, an HP 7673 controller, a JASCO 880-PU intelligent HPLC pump, and a BISCHOFF RI-Detector 8110 . The substrates to be analyzed were eluted in isocratic mode with $0.005 \mathrm{M} \mathrm{H}_{2} \mathrm{SO}_{4}$ at a rate of $0.60 \mathrm{~mL} / \mathrm{min}$. Solutions of pure sugars (glucose, galactose, lactose) and lactic acid were used for external calibration.

\section{PHA determination}

The frozen and lyophilized biomass pellets from the cell dry mass determination were used for measuring the PHA concentration in the biomass and PHA's monomeric composition according to Braunegg's method (36). Briefly, PHA in the lyophilized biomass pellets was simultaneously extracted by chloroform and transesterificated by acidic methanolysis; hexanoic acid acted as internal standard. The methanolysis cocktail was analyzed using an HP 5890 Series II gas chromatograph (GC) equipped with a 5 m HP 1 capillary pre-column and 30 m HP5 column and a flame ionization detector (FID) for detecting the volatile methyl esters of the PHA building blocks. Helium was used as carrier gas, $\mathrm{H}_{2}$ and synthetic air (oxygen source) as detector gases, and nitrogen as auxiliary gas. The injection volume amounted to $1 \mu \mathrm{L}$, the split ratio was $1 / 10$. Pure Biopol ${ }^{\mathrm{Tm}}$ poly $(3 \mathrm{HB}-\mathrm{co}-3 \mathrm{HV})$ copolyester with a $3 \mathrm{HV}$ content of $19.1 \%$ was used for external calibration.

\section{Results}

\section{Preliminary testing of different complex nitrogen sources}

$H$. pseudoflava was grown for 24 hours in media with inorganic nitrogen (ammonia sulfate) and $2 \mathrm{~g} / \mathrm{L}$ of different complex nitrogen sources. As reference, a culture with ammonium sulfate 


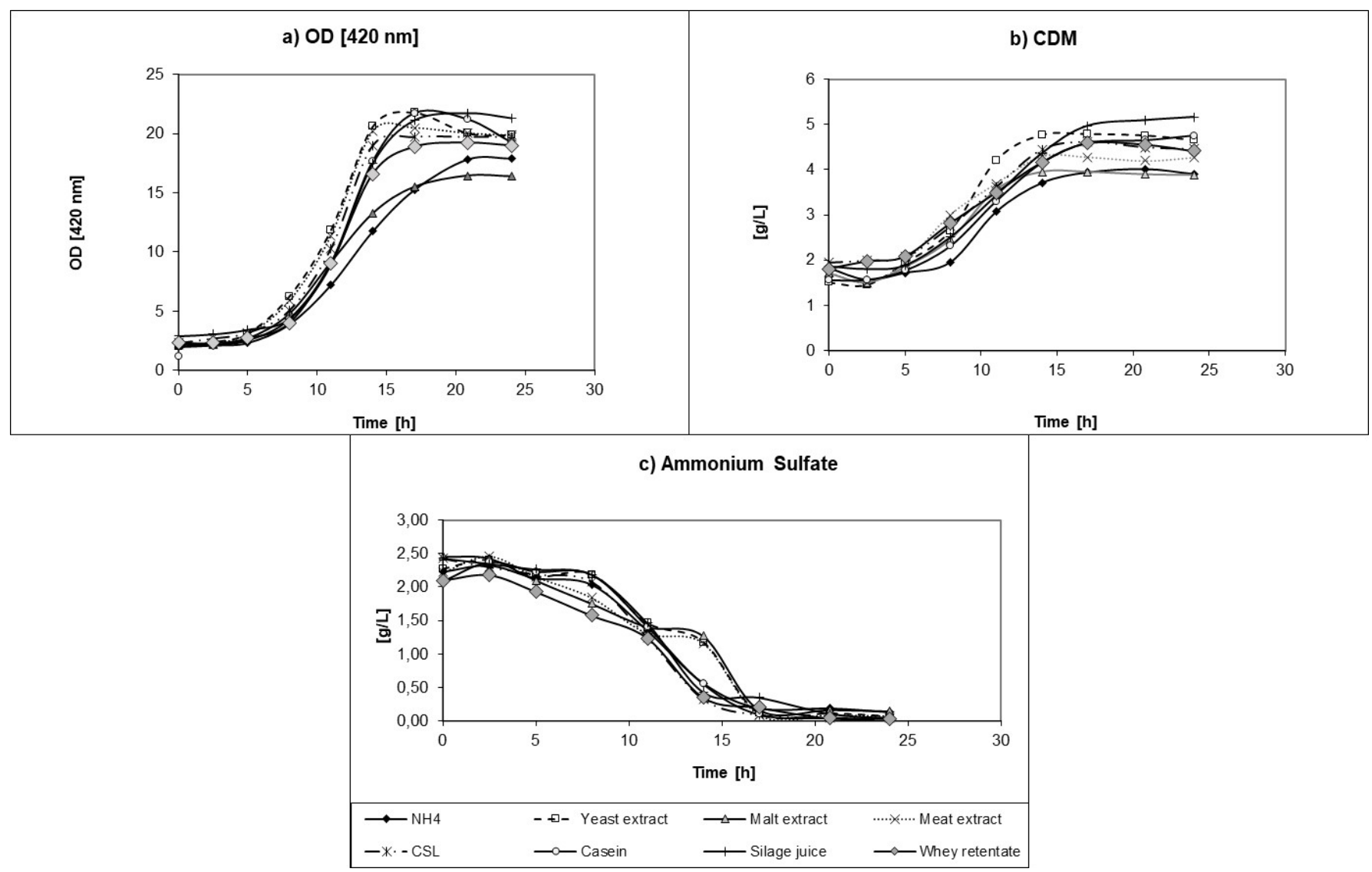

Figure 2. Time patterns of OD (a), CDM (b), and inorganic nitrogen source ammonium sulfate (c). H. pseudoflava cultivated on shaking flask scale for $24 \mathrm{~h}$ on hydrolyzed whey permeate as carbon source and ammonium sulfate as inorganic nitrogen sources; comparison of growth patterns with addition of different complex nitrogen sources (yeast extract, CSL, casein hydrolysate, malt extract, pressed grass silage juice, meat extract, and not hydrolyzed whey retentate).

as only nitrogen source was used. Figs 2 a-c show the OD values and concentrations of CDM and ammonium sulfate for all cultivation setups.

Increase of both OD and CDM with time demonstrate that most of the complex nitrogen sources tested definitely enhanced growth rate and biomass formation of $H$. pseudoflava. Highest $\mathrm{OD}$ and $\mathrm{CDM}$ values were reached when adding pressed grass silage juice, casein peptone or yeast extract as complex nitrogen sources. The lag phase (about $5 \mathrm{~h}$ ) was however in the same range for all setups, though a bit shorter when using casein peptone and yeast extract. The higher CDM val- ues for pressed grass silage juice at the end of the experiment could be explained by presence of complex sources, which can serve as additional substrate utilized only after the main carbon source (glucose and galactose from hydrolyzed whey permeate) is already depleted (27).

Table 2 collects growth rates $\left(r_{X}\right)$ and specific growth rates ( $\mu$ ) calculated from the OD values. Both $r_{X}$ and $\mu$ calculated between 5 and $8 \mathrm{~h}$ are similar for all cultures except the ones supplied with yeast and meat extract. In these setups, growth rates and specific growth rates are higher compared to the others, evidencing that the lag phase is shorter when yeast or meat

Table 2. Growth rates $\left(r_{x}\right)$ and specific growth rates $(\mu)$ of cultures from the exponential growth phase expressed based on OD values

\begin{tabular}{|c|c|c|c|c|c|c|c|c|c|}
\hline & Time & $\begin{array}{c}\text { Only inorg. } \\
\text { N-source }\end{array}$ & $\begin{array}{c}\text { Yeast } \\
\text { extract }\end{array}$ & $\begin{array}{c}\text { Malt } \\
\text { extract }\end{array}$ & $\begin{array}{c}\text { Meat } \\
\text { extract }\end{array}$ & CSL & $\begin{array}{c}\text { Casein } \\
\text { Hydrolysate }\end{array}$ & $\begin{array}{c}\text { Pressed } \\
\text { grass silage } \\
\text { juice }\end{array}$ & $\begin{array}{c}\text { Whey } \\
\text { retentate }\end{array}$ \\
\hline $\boldsymbol{r}_{\boldsymbol{x}}$ (dOD/dt) & $5-8 \mathrm{~h}$ & 0.52 & 1.05 & 0.70 & 0.94 & 0.63 & 0.60 & 0.31 \\
\hline $\boldsymbol{r}_{\boldsymbol{x}}(\mathbf{d O D} / \mathbf{d t})$ & $8-11 \mathrm{~h}$ & 1.11 & 1.88 & 1.64 & 1.84 & 1.74 & 1.58 & 1.53 & 1.68 \\
\hline $\boldsymbol{\mu ( 1 / h )}$ & $5-8 \mathrm{~h}$ & 0.22 & 0.34 & 0.26 & 0.31 & 0.20 & 0.24 & 0.09 & 0.16 \\
\hline $\boldsymbol{\mu}(\mathbf{1} / \mathbf{h})$ & $8-11 \mathrm{~h}$ & 0.28 & 0.30 & 0.34 & 0.31 & 0.34 & 0.37 & 0.35 & 0.42 \\
\hline
\end{tabular}

$r_{x}=\mathrm{dOD} / \mathrm{dt} ; \mu=r_{x} / \mathrm{OD}$ 
a) $O D[420 \mathrm{~nm}]$

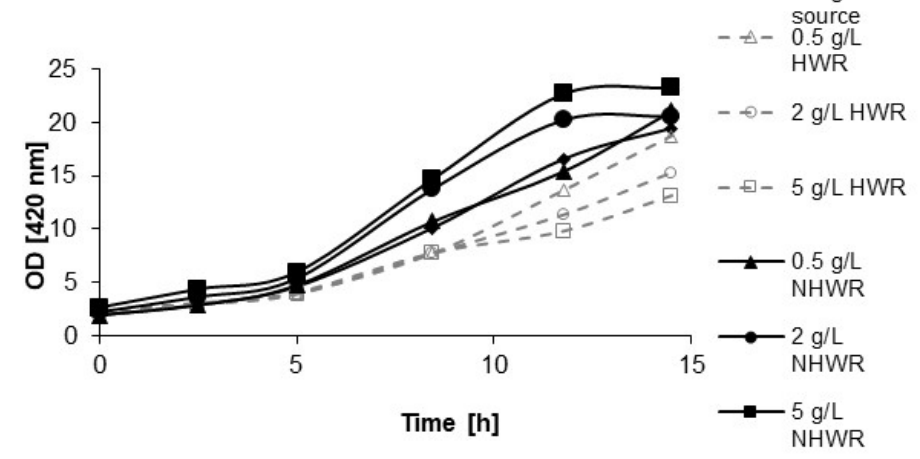

b) $\mathrm{CDM}$

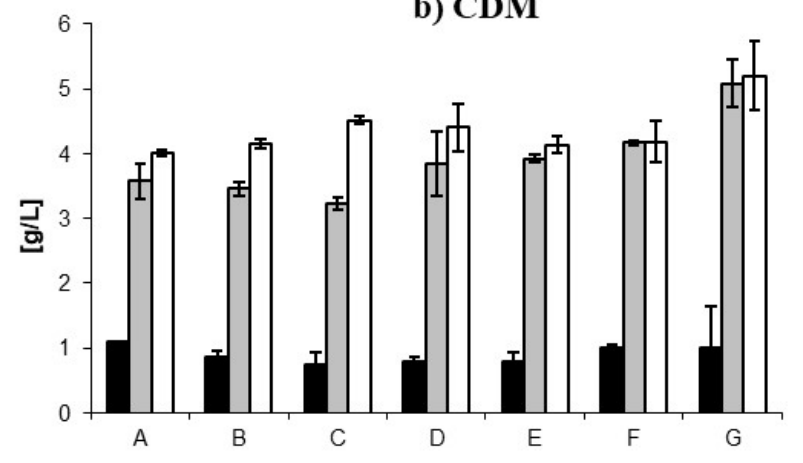

Figure 3. (a) times curves of OD $(420 \mathrm{~nm})$ during the phase of microbial growth ( $\mathrm{t}=0-15 \mathrm{~h})$; (b): CDM at time $0 \mathrm{~h}$ (black bars), 11.75 h (grey bars), and $26.25 \mathrm{~h}$ (white bars); A: only inorganic N-source, B: 0.5 g/L HWR, C: 2 g/L HWR, D: 5 g/L HWR, E: 0.5 g/L NHWR, F: 2 g/L NHWR, G: 5 g/L NHWR. H. pseudoflava on hydrolyzed whey permeate as carbon source and different additions of HWR or NHWR. Error bars indicate the deviations between two parallel cultivations.

extract is added to the cultivation medium. However, when the rates are calculated between hours 8 and 11 (exponential growth phase), higher values for $r_{X}$ and $\mu$ were observed for all complex sources in comparison to setups containing only inorganic nitrogen source. For the novel complex nitrogen source whey retentate, $r_{X}$ was similar to the commercial complex nitrogen sources (nota bene: among them, especially yeast extract significantly contributes to the cultivation costs!) and to pressed grass silage juice. $\mu$ for retentate $(0.421 / \mathrm{h})$ obtained for whey retentate setups, however, outperformed results for all other studied nitrogen sources during the phase of exponential growth.

\section{Comparison of hydrolyzed and non-hydrolyzed whey retentate as complex nitrogen source}

Hydrolyzed and not hydrolyzed whey retentate (HWR and NHWR, respectively) were added in different concentrations to a H3 medium containing hydrolyzed whey permeate as carbon source, and ammonium sulfate as inorganic nitrogen source. Hydrolysis was carried out in order to generate amino acids and smaller peptides, which might me more easily accessible by the cells than the whole whey proteins. Hence, the effect of HWR and NHWR on the growth phase of H. pseudoflava was comparatively studied. After 26.25 hours, the cultivations were stopped, as at that point all the cultures had already reached the PHA accumulation phase. Fig. 3a shows the time curves of OD for all setups during the phase of microbial growth $(t=0-15 \mathrm{~h})$. Here, it can be seen that the exponential growth of $H$. pseudoflava, expressed as OD during time, is significantly enhanced by the addition of NHWR as complex nitrogen source. On the contrary, growth was somewhat inhibited when HWR was added, if compared to the cultures containing ammonium sulfate as sole nitrogen source. Time curves for the cultures with $0.5 \mathrm{~g} / \mathrm{L}$ HWR showed a trend almost identical to the ones containing only inorganic nitrogen source. Fig. $3 b$ shows the CDM values of the different cultivation setups after $0,11.75$ and 26.25 h. CDM values obtained after $26.25 \mathrm{~h}$ are approximately equal in all cultures (about $4 \mathrm{~g} / \mathrm{L}$ ), except the culture supplied with $5 \mathrm{~g} / \mathrm{L} \mathrm{NHWR}$, where the CDM is higher (about $5 \mathrm{~g} / \mathrm{L}$ ). In the cultures supplied with NHWR, CDM did not significantly increase in the period between 11.75 and $26.25 \mathrm{~h}$. In the cultures with only inorganic nitrogen source (ammonium sulfate) and those supplied with HWR, the CDM values typically were lower after $11.75 \mathrm{~h}$ than for setups containing NHWR, indicating a slower growth rate; however, after $26.25 \mathrm{~h}$, CDM reached values similar to those observed in setups supplied with NHWR.

The same conclusion can be made from Figs. $4 a$ and $b$, which show the utilization of ammonium sulfate (Fig. 4a) and total sugars (Fig. 4b) during the cultivations. Studying the results presented in Fig. 4a, it is evident that ammonium is much faster utilized in those cultures containing NHWR as complex nitrogen source than in those containing HWR, indicating that growth is enhanced by this protein-rich additive. However, some important amino acids are maybe not present in retentate and therefore still have to be synthesized from the inorganic nitrogen source. The lower conversion rate for the inorganic nitrogen source in setups containing HWR also correlates with slower growth in these setups, and also evidences that the strain might resort to some components from HWR (amino acids, peptides) to synthesize its own proteins prior to synthesizing them de novo from inorganic nitrogen source. This matches the trend of sugar conversion, as displayed in Fig. 4b. Less sugar (sum of glucose and galactose) is utilized in the setups containing HWR (Fig. 4b). This lower sugar consumption correlates with the lower ammonium sulfate consumption rates shown in Fig. 4a. After 11.75 hours, most of the sugars had been depleted in the cultures with 2 and $5 \mathrm{~g} / \mathrm{L} \mathrm{NHWR}$, while in the medium containing 2 and $5 \mathrm{~g} / \mathrm{L} \mathrm{HWR}$, considerable amounts of sugar were still detected. At the end of the experiment $(t=26.25 \mathrm{~h})$, sugar concentration was at a low level below $1 \mathrm{~g} / \mathrm{L}$ for all setups. Figs. $4 \mathrm{c}$ and $\mathrm{d}$ show the individual utilization of glucose and galactose, the two sugars obtained by hydrolyzing whey permeate (nota bene: lactose was not detected due to complete hydrolysis). After 11.75 hours, glucose was completely depleted 


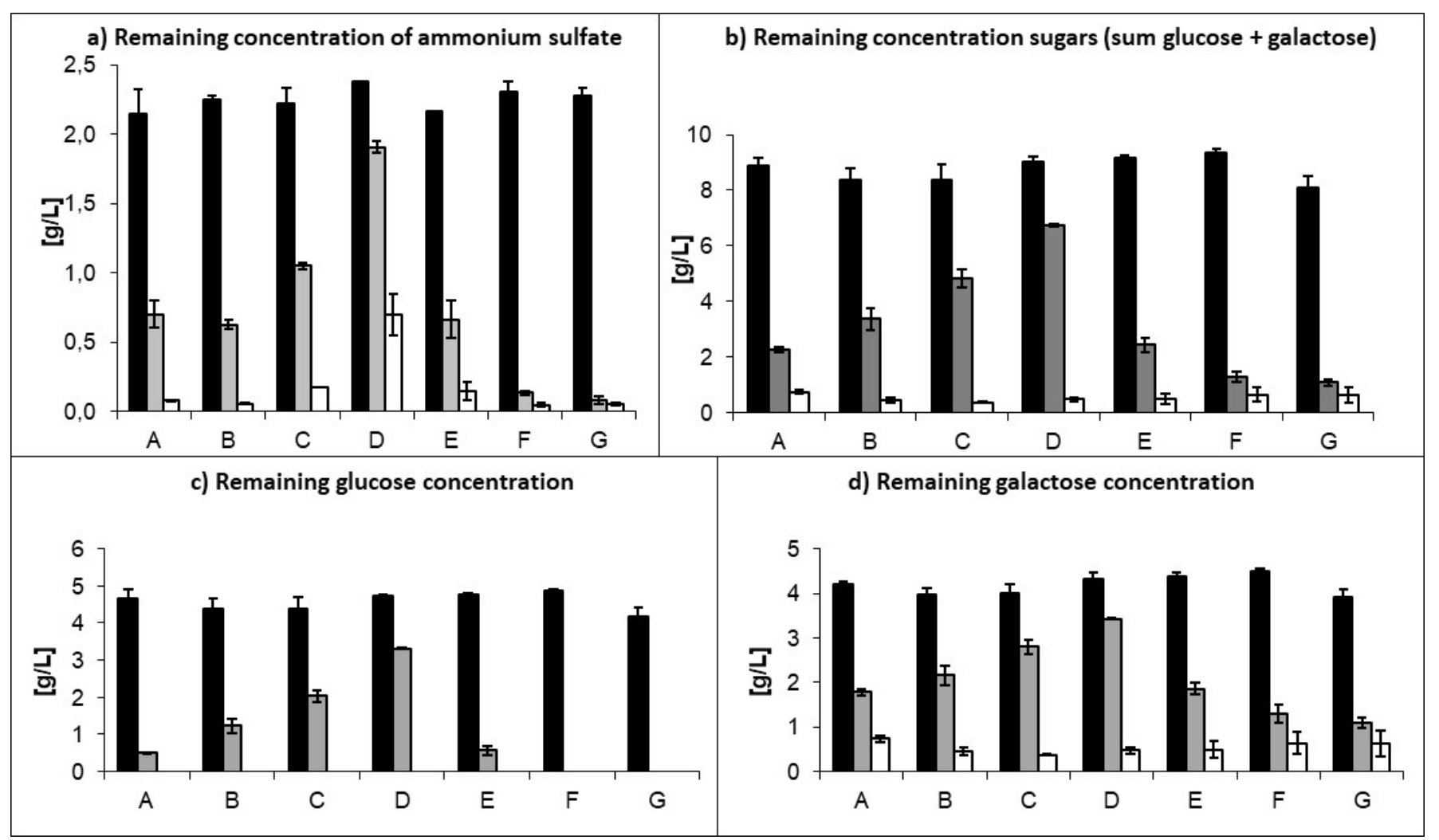

Figure 4. Remaining concentrations of ammonium sulfate (a), total sugars (sum glucose + galactose, b), glucose (c), and galactose at time $0 \mathrm{~h}$ (black bars), $11.75 \mathrm{~h}$ (grey bars), and $26.25 \mathrm{~h}$ (white bars). A: only inorganic N-source, B: $0.5 \mathrm{~g} / \mathrm{L}$ HWR, C: 2 g/L HWR, D: 5 g/L HWR, E: 0.5 g/L NHWR, F: 2 g/L NHWR, G: 5 g/L NHWR. H. pseudoflava on hydrolyzed whey permeate as carbon source and different additions of HWR or NHWR. Error bars indicate the deviations between two parallel cultivations.

in the cultures containing 2 and $5 \mathrm{~g} / \mathrm{L}$ whole whey retentate, while in cultures with HWR, only about $25 \%$ ( $5 \mathrm{~g} / \mathrm{L}$ hydrolyzed retentate) or $50 \%$ ( $2 \mathrm{~g} / \mathrm{L}$ hydrolyzed retentate), respectively, of originally present glucose were converted. At the end of the experiments $(t=26.25 \mathrm{~h})$, glucose was entirely depleted in all setups. The same trend was observed for galactose. In cultures containing only inorganic nitrogen or those supplied with 0.5 g/L NHWR or HWR, very similar galactose utilization was observed; for setups with 2 or $5 \mathrm{~g} / \mathrm{L}$ NHWR, only about $1 \mathrm{~g} / \mathrm{L}$ galactose remained after $11.75 \mathrm{~h}$. Remarkably, some quantity of galactose was still detected in all setups at the end of the cultivations, indicating the preference of $H$. pseudoflava for glucose when supplied together with galactose.

Fig. 5 shows the PHA concentrations (Fig. 5a) and residual biomass (CDM minus PHA) concentrations (Fig. 5b) in the cultures at different times. Importantly, in all cases, $\mathrm{PHB}$ homopolyester was synthesized; $3 \mathrm{HV}$ or $4 \mathrm{HB}$ building blocks were not detected via GC-FID determination, which differs from a previous report on this organism (15), but substantiates older literature for this strain-substrate combination $(16,17)$. In the cultures not containing complex nitrogen and in those containing $0.5 \mathrm{~g} / \mathrm{L}$ HWR or NHWR, highest PHB concentrations (range 0.6 to $0.8 \mathrm{~g} / \mathrm{L}$ ) were achieved only at the end of the experiment $(t=26.25 \mathrm{~h})$, while for setups containing 2 and 5 g/L HWR, PHB concentrations were by far higher after $11.75 \mathrm{~h}$
(0.4 to $0.5 \mathrm{~g} / \mathrm{L}$ ) than after $26.25 \mathrm{~h}$ (only traces of PHB); hence, the produced polymer was largely degraded. Setups containing 2 or $5 \mathrm{~g} / \mathrm{L}$ HWR displayed similar PHB concentrations ( 0.6 and $0.5 \mathrm{~g} / \mathrm{L}$, respectively) after 11.75 and $26.25 \mathrm{~h}$. Also production of residual biomass proceeded until the end of the experiment for all setups, with highest values (4-5 g/L) being obtained for setups supplied with $5 \mathrm{~g} / \mathrm{L}$ NHWR (G). After $11.75 \mathrm{~h}$, both sugars and ammonium were still present in all setups; these substrates can be converted to residual biomass (from conversion of sugars and ammonium) and PHB (only from sugars). As ammonium was present in these flasks even after $26.25 \mathrm{~h}$, the cells were able to produce biomass in the period between 11.75 and $26.5 \mathrm{~h}$. However, also in these cultures, the concentrations of exogenous carbon source (sugars) were very low at the end of the experiment, evidencing that $\mathrm{PHB}$ accumulated within the first phase of the experiment (until $t=11.75 \mathrm{~h}$ ) was remobilized by the cells in the second phase ( $t=11.75$ to $26.25 \mathrm{~h}$ ) for formation of residual biomass. This is well substantiated by the values for volumetric productivity shown in Fig. 5d; here, negative values for PHA productivity calculated for setups C and D (higher concentrations of HWR of $2 \mathrm{~g} / \mathrm{L}$ and $5 \mathrm{~g} / \mathrm{L}$, respectively) indicate intracellular PHA degradation. The fact that cultures $\mathrm{C}$ and $\mathrm{D}$ still contained high amounts of ammonium sulfate after $11.75 \mathrm{~h}$ (about $1 \mathrm{~g} / \mathrm{L}$ and $2 \mathrm{~g} / \mathrm{L}$, respectively) also explains the lower PHA concentrations in these setups after $11.75 \mathrm{~h}$ (Fig. 


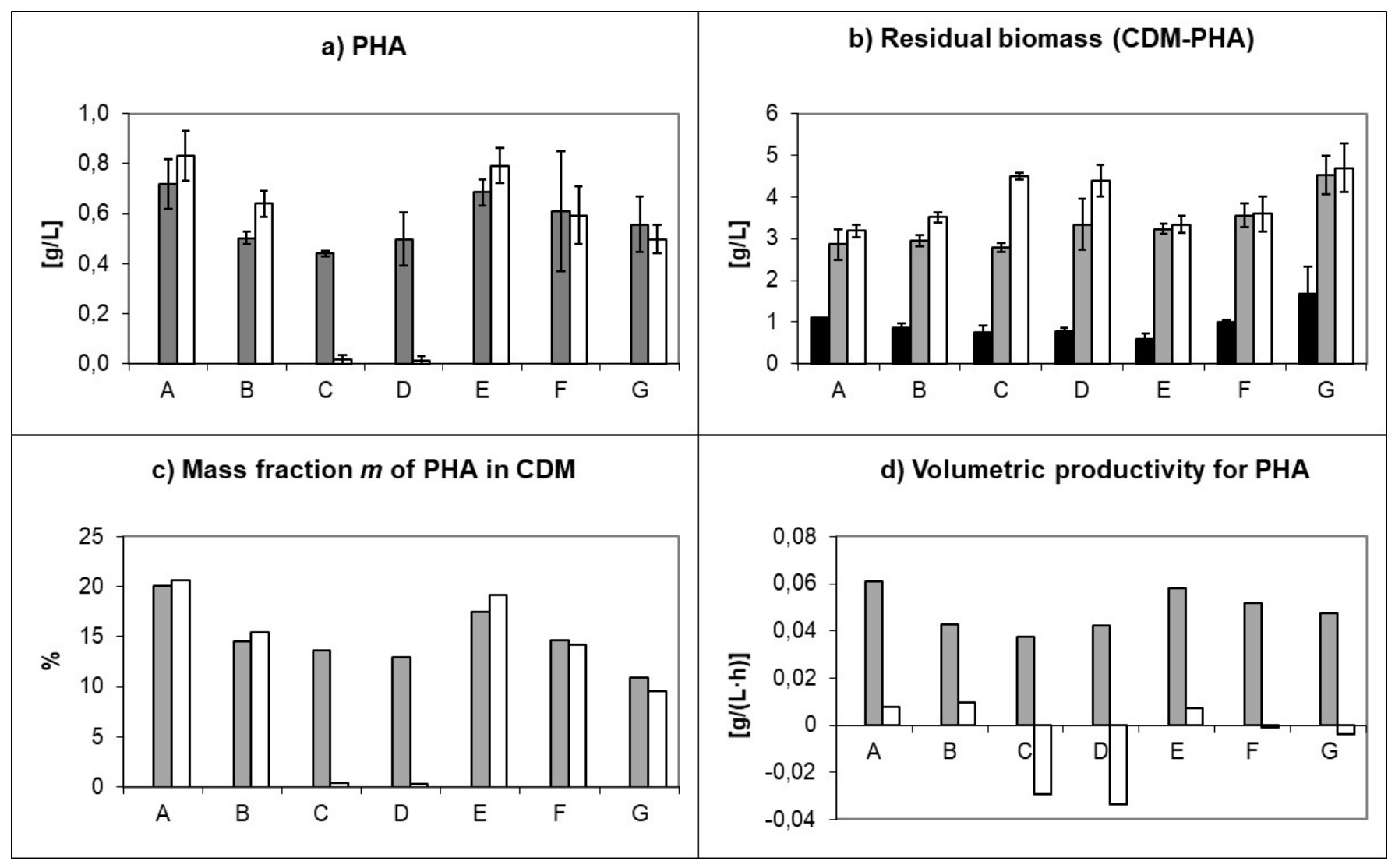

Figure 5. Concentrations of PHA (a), residual biomass (CDM minus PHA, b), mass fraction $m$ of PHA in CDM (c), and volumetric PHA productivity at time $0 \mathrm{~h}$ (black bars), $11.75 \mathrm{~h}$ (grey bars), and $26.25 \mathrm{~h}$ (white bars). A: only inorganic N-source, B: $0.5 \mathrm{~g} / \mathrm{L} \mathrm{HWR,} \mathrm{C:} 2 \mathrm{~g} / \mathrm{L}$ HWR, D: 5 g/L HWR, E: 0.5 g/L NHWR, F: 2 g/L NHWR, G: 5 g/L NHWR. H. pseudoflava on hydrolyzed whey permeate as carbon source and different additions of HWR or NHWR. Error bars indicate the deviations between two parallel cultivations.

$5 a)$; at that point, these cultures were not exposed yet to nitrogen limitation generally favoring PHB biosynthesis (38). For all other setups, residual biomass production between hours $\mathrm{t}=$ 11.75 and $26.25 \mathrm{~h}$ was insignificant. In setups containing 2 and $5 \mathrm{~g} / \mathrm{L}$ NHWR, both ammonium and sugars were almost depleted after 11.75 hours (Fig. 4a, b), which prevented formation of both residual biomass and PHB (Fig. 5a, b). Nitrogen limitation in setups A (only inorganic nitrogen) is also evidenced by the highest intracellular PHA mass fractions $(m)$ calculated as displayed in Fig. 5c; after 26.25 h, about 20 wt.-\% were obtained for setups without complex nitrogen source, which is in a similar range as for setups containing $0.5 \mathrm{~g} / \mathrm{L}$ NHWR (E). At that time, the mass fraction of PHA in setups C and D was already below 1 wt.- $\%$.

Based on measured OD values, $r_{X}$ and $\mu$ were calculated for these cultivations. $r_{X}$ and $\mu$ were first calculated between $\mathrm{t}=5$ to $8.75 \mathrm{~h}$, when biomass growth was exponential for all cultures (Fig. 6a, b). After 11.75 h, growth was still exponential for all cultures containing HWR as complex nitrogen source. Therefore, growth rates and $\mu$ were calculated also for the period between $t=5$ to 11.75 h (Fig. $6 c, d$ ). It can also be seen from Fig. $\mathbf{6} \mathbf{a}$ and $\mathbf{b}$ that $r_{X}$ and $\mu$ for cultures containing NHWR increased with increasing concentration of this additive when adding it at a quantity of 2 and $5 \mathrm{~g} / \mathrm{L}$, while supplementation with $5 \mathrm{~g} / \mathrm{L}$
NHWR further increased $r_{X}$ only insignificantly, and values for $\mu$ were almost the same when comparing setups with 2 and 5 g/L NHWR.

Mathematical modelling of both growth and product formation phase PHA production process has recently become an emerging topic, helping to better understand and optimize such bioprocesses, which ultimately shortens the way towards industrial realization and helps avoiding technological deadlocks already at a very early stage of process development $(39,40)$. In this context, it is well visible from all time curves illustrated in Figs. 6a-d that HWR does not increase $r_{X}$ and $\mu$, but, on the contrary, even displays inhibiting effects. Therefore, a Dixon plot was developed to calculate the inhibition constant $K_{i}$ of HWR on $H$. pseudoflava thriving under described conditions; based on this plot, $K_{i}$ for HWR was determine to amount to $6.1 \mathrm{~g} / \mathrm{L}$ (Fig. 7a).

For the setups containing NHWR as complex nitrogen source, Haldane and Monod kinetics, which reflect the dependence of $\mu$ on substrate concentration, were modelled using the solver function in Microsoft excel program (Fig. 7b, c). Here, it should be emphasized that the calculated kinetic constants do not refer to NHWR alone, but to the combination of the inorganic nitrogen and NHWR. The substrate concentrations used in the calculations only reflect the concentration 


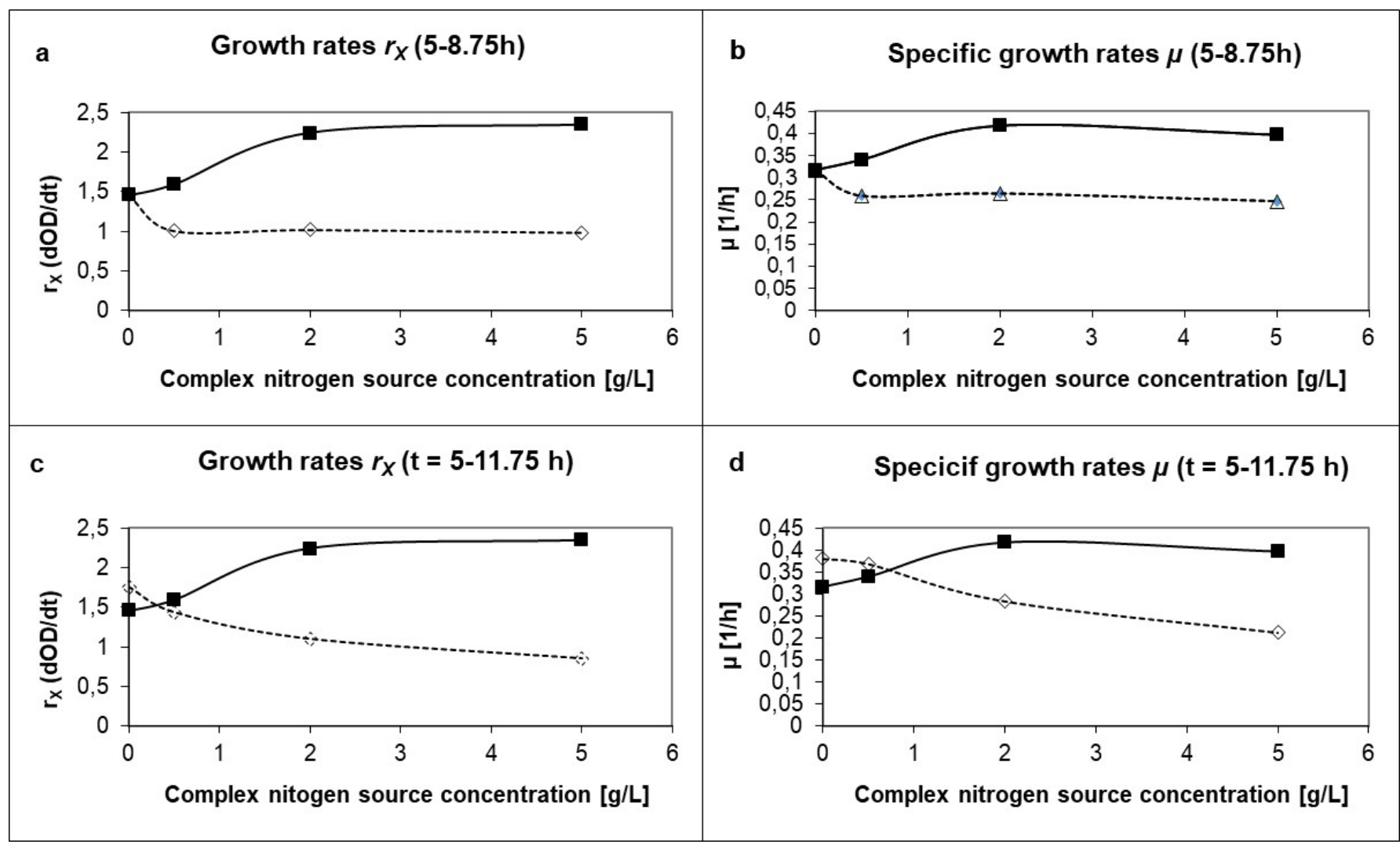

Figure 6. Growth rates $r_{x}$ and specific growth rates $\mu$ for time interval between $\mathrm{t}=5$ and $8.75 \mathrm{~h}$ (a and b, respectively), and for time interval between $\mathrm{t}=5$ and $11.75 \mathrm{~h}$ (c and d, respectively). H. pseudoflava on hydrolyzed whey permeate as carbon source and different additions of HWR or NHWR. Full lines with full symbols: NHWR; dashed lines with open symbols: HWR. $r_{x}=d O D / d t ; \mu=r_{x} / O D$

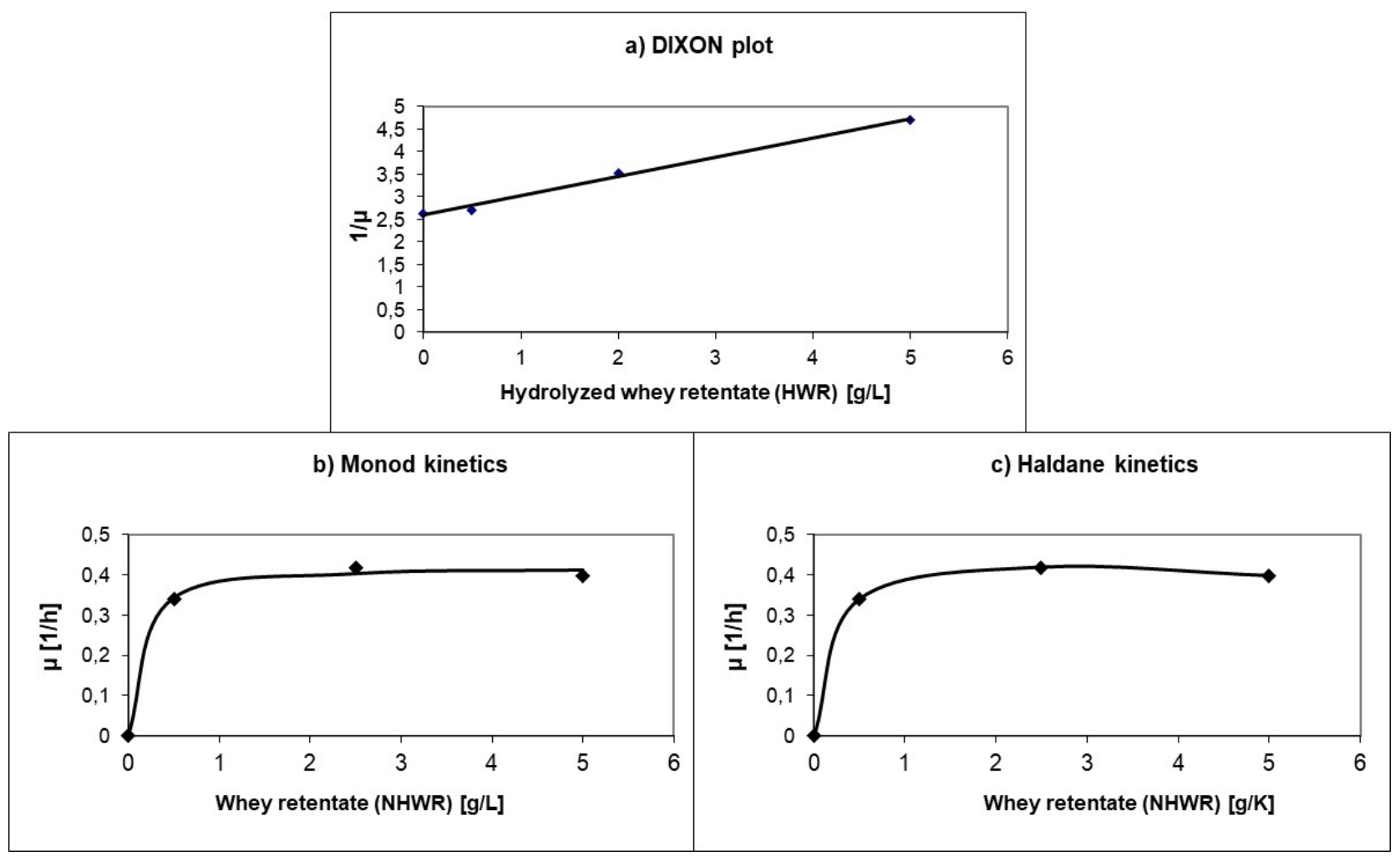

Figure 7. a) Dixon plot to determine inhibition constant $K_{i}$ for HWR on growth of $H$. pseudoflava; b) Monod kinetics, c) Haldane kinetics for utilization of NHWR. H. pseudoflava on hydrolyzed whey permeate as carbon source and different additions of HWR $H$. pseudoflava on hydrolyzed whey permeate as carbon source and different additions of HWR or NHWR. 
Table 3. Kinetic constants for whey retentate for $\mathrm{H}$. pseudoflava in a medium with $2 \mathrm{~g} / \mathrm{L}$ ammonium sulfate as inorganic nitrogen source established according to Haldane and Monod

\begin{tabular}{|c|c|c|c|}
\hline Equation & $K_{s}$ & $\mu_{\max }$ & $K_{i}$ \\
\hline Haldane & 0.18 & 0.46 & 14.98 \\
\hline Monod & 0.11 & 0.42 & - \\
\hline
\end{tabular}

of NHWR. Therefore, the kinetic constants calculated cannot be directly compared with situations where whey retentate acts as sole nitrogen source. The equations for Haldane and Monod kinetics are shown in equations 1 and 2, respectively.

$$
\begin{array}{ll}
\mu=\frac{\mu_{\max }}{1+\frac{K_{s}}{S}+\left(\frac{S}{K_{i}}\right)^{n}} & \text { equation 1: Monod kinetics } \\
\mu=\frac{\mu_{\max }}{1+\frac{K_{s}}{S}} & \text { equation 2: Haldane kinetics }
\end{array}
$$

$\mu$ : specific growth rate; $\mu_{\text {max. }}=$ maximum specific growth rate; $K_{S}=$ growth constant; $S=$ substrate concentration; $K_{i}=$ inhibition constant

Based on the Haldane model, a $K_{S}$ value of $0.18 \mathrm{~g} / \mathrm{L}$ was calculated; this signifies that, when the concentration of the inorganic nitrogen source ammonium sulfate amounts to $2 \mathrm{~g} / \mathrm{L}$, the value for $\mu$ is half of the maximum which could be achieved when adding whole whey retentate at a concentration of 0.18 g/L. $K_{s}$ calculated based on Monod's model was somewhat lower $(0.11 \mathrm{~g} / \mathrm{L})$; hence, when relying on Monod, less substrate is needed for an equally fast growth. $\mu_{\text {max. }}$, which reflects the maximum specific growth rate that can be achieved by a given strain-substrate combination, had similar values $(0.46 \mathrm{1} / \mathrm{h}$ and $0.42 \mathrm{l} / \mathrm{h}$ ) when using either Haldane or Monod, respectively. In addition, an inhibition constant for NHWR can be calculated when applying the Haldane equation, which amounted to about $15 \mathrm{~g} / \mathrm{L}$. Table 3 summarizes the calculated kinetic constants for the two kinetic equations.

\section{Discussion}

\section{Preliminary testing of different complex nitrogen sources}

With all complex nitrogen sources (except malt extract, which may contain inhibiting compounds (37)) $\mathrm{H}$. pseudoflava grew faster and achieved higher OD and CDM values; this attracts the attention on these complex additives to be used in cultivations of $H$. pseudoflava under controlled conditions on bioreactor scale. The cost of such additives must, however, be set in relation to the de facto achievable increase of biomass and overall productivity compared to ammonium sulfate when applied as sole nitrogen source to critically assess their economic feasibility; this will require detailed techno-economic calculations from bioreactor cultivation setups.

As discussed above, when whey permeate is used as carbon source, it would be convenient to use also the whey retentate fraction as nitrogen source. In an optimized scenario, PHA will be produced in the same factory as cheese whey, which means that both the permeate and the retentate would be available for the PHA production in house without generating any transportation costs (29). That way, reduction of a waste material stream (whey) from the cheese production process would conveniently be combined with enhanced growth of the PHA producing bacteria. For this reason, the subsequent experiment was carried out for a more in depth analysis of whey retentate as biotechnological nitrogen source.

\section{Comparison of hydrolyzed and non-hydrolyzed whey retentate as complex nitrogen source}

Growth and growth rate of the auspicious PHA production strain $H$. pseudoflava can be enhanced by adding rather low quantities (up to $5 \mathrm{~g} / \mathrm{L}$ ) of NHWR to a $\mathrm{H} 3$ medium containing hydrolyzed whey permeate as carbon source and $2 \mathrm{~g} / \mathrm{L}$ of ammonium sulfate as inorganic nitrogen source. According to Haldane's kinetics calculated in this study, whey retentate becomes inhibiting only at concentrations exceeding $15 \mathrm{~g} / \mathrm{L}$. The kinetic effect of adding either $2 \mathrm{~g} / \mathrm{L}$ or $5 \mathrm{~g} / \mathrm{L}$ is negligible; thus, supplementation of $2 \mathrm{~g} / \mathrm{L}$ NHWR can be considered sufficient to positively impact the process.

In contrast, the experimental results clearly show that addition of HWR results in lower $r_{X}$ and $\mu$ for this strain, and should therefore not be used in its present form as complex nitrogen source for $H$. pseudoflava. The reason for this inhibiting effect might be the higher salt concentration of HWR $(6 \mathrm{M} \mathrm{NaCl}$ added to $1 \mathrm{~kg}$ of retentate via $\mathrm{HCl}$ for hydrolysis and $\mathrm{NaOH}$ for neutralization) and/or formation of growth inhibiting substances, which might be formed during the acidic hydrolysis as reported in previous literature (41). The calculated $K_{i}$ value $(6.1 \mathrm{~g} / \mathrm{L})$ is rather high in comparison to other additives used on shaking flaks scale for cultivations of PHA producing organisms; in the case of Pseudomonas hydrogenovora (today: Paraburkholderia fungorum), a $K_{i}$ of $1.84 \mathrm{~g} / \mathrm{L}$ was determined for the addition of the $3 \mathrm{HV}$-precursor sodium valerate, when hydrolyzed whey permeate was used as main carbon source (42). Hence, the inhibiting effect of HWR obtained by acidic treatment of whey retentate is not exceptionally high.

However, it appears logical that, after hydrolysis of whey retentate, its amino acids and small peptides should be better 
available for the strain if compared to whole proteins, which have to hydrolyzed by the strain before being accessible for utilization. With acidically hydrolyzed retentate, this was however not the case. Therefore, it should also be tested in follow-up experiments if enzymatically (proteases) hydrolyzed whey retentate would be advantageous compared to NHWR. In addition, desalination of acidic hydrolysates and simple methods for detoxification to remove inhibitors should be tested as subsequent steps. Such detoxifications, based on overliming, active carbon, and lignite, performed successfully in the past when hydrolyzing, e.g., lignocellulose materials to generate inexpensive substrates for other PHA production strains, as described in various literature reports (43-45).

\section{Acknowledgement}

The authors gratefully acknowledge the financial support provided the European Commission by granting the collaborative project "Dairy industry waste as source for sustainable polymeric material production", Acronym WHEYPOL, GRD2-2000-30385. In this context, special credits go to our industrial project partner Latterie Vicentine S.c.a., Bressanvido (VI), Veneto, Italy, represented by Luigi Sibilin, for producing and delivering whey permeate and whey retentate from their Asiago DOC cheese production process, which were applied in this study.

\section{Conflict of interest statement}

The authors declare that they have no conflict of interest.

\section{References}

1. Haider TP, Völker C, Kramm J, Landfester K, Wurm FR. Plastics of the future? The impact of biodegradable polymers on the environment and on society. Angew Chem Int Edit 2019; 58: 50-62

2. Koller M. Switching from petro-plastics to microbial polyhydroxyalkanoates (PHA): the biotechnological escape route of choice out of the plastic predicament? The EuroBiotech Journal 2019; 3(1): 32-44.

3. Narodoslawsky M, Shazad K, Kollmann R, Schnitzer H. LCA of PHA production-Identifying the ecological potential of bio-plastic. Chem Biochem Eng Q 2015; 29(2): 299-305.

4. Koller M, Maršálek L, Miranda de Sousa Dias M, Braunegg G. Producing microbial polyhydroxyalkanoate (PHA) biopolyesters in a sustainable manner. New Biotechnol 2017; 37(A): 24-38.

5. Kourmentza C, Plácido J, Venetsaneas N, Burniol-Figols A, Varrone C, Gavala HN, Reis MAM. Recent advances and challenges towards sustainable polyhydroxyalkanoate (PHA) production. Bioengineering 2017; 4(2): 55.

6. Bugnicourt E, Cinelli P, Lazzeri A, Alvarez VA. Polyhydroxyalkanoate (PHA): Review of synthesis, characteristics, processing and potential applications in packaging. eXPRESS Polym Lett 2014; 8(11): 791-808.

7. Khosravi-Darani K, Bucci DZ. Application of poly(hydroxyalkanoate) in food packaging: Improvements by nanotechnology. Chem Biochem Engineering Q 2015; 29(2): 275-285.

8. Koller M. Biodegradable and biocompatible polyhydroxy-alkanoates (PHA): Auspicious microbial macromolecules for pharmaceutical and therapeutic applications. Molecules 2018; 23(2): 362.

9. Drosg B, Fritz I, Gattermayr F, Silvestrini L. Photo-autotrophic production of poly(hydroxyalkanoates) in cyanobacteria. Chem Biochem Engineering Q 2015; 29(2): 145-156.
10. Troschl C, Meixner K, Drosg B. Cyanobacterial PHA productionReview of recent advances and a summary of three years' working experience running a pilot plant. Bioengineering 2017: 4(2): 26.

11. Koller M. Production of polyhydroxyalkanoate (PHA) biopolyesters by extremophiles. MOJ Polym Sci 2017; 1(2): 1-19.

12. Koller M, Obruca S, Pernicova I, Braunegg G. Physiological, kinetic, and process engineering aspects of polyhydroxyalkanoate biosynthesis by extremophiles. In: Williams H, Kelly P (Eds.) Polyhydroxyalkanoates: Biosynthesis, Chemical Structures and Applications. 2018. ISBN 978-1-53613-439-1; Nova Science Publishers, New York, pp. 1-70.

13. Willems A, Busse J, Goor M, Pot B, Falsen E, Jantzen, E, et al. Hydrogenophaga, a new genus of hydrogen-oxidizing bacteria that includes Hydrogenophaga flava comb. nov.(formerly Pseudomonas flava), Hydrogenophaga palleronii (formerly Pseudomonas palleronii), Hydrogenophaga pseudoflava (formerly Pseudomonas pseudoflava and "Pseudomonas carboxydoflava"), and Hydrogenophaga taeniospiralis (formerly Pseudomonas taeniospiralis). Int J Syst Evol Microbiol1989; 39(3): 319-333.

14. Mahmoudi M, Baei MS, Najafpour GD, Tabandeh F, Eisazadeh H. Kinetic model for polyhydroxybutyrate (PHB) production by $\mathrm{Hy}$ drogenophaga pseudoflava and verification of growth conditions. Afr J Biotechnol 2010; 9(21): 3151-3157.

15. Povolo S, Romanelli MG, Basaglia M, Ilieva VI, Corti A, Morelli A, Chiellini E, Casella S. Polyhydroxyalkanoate biosynthesis by $\mathrm{Hy}$ drogenophaga pseudoflava DSM1034 from structurally unrelated carbon sources. New Biotechnol 2013; 30(6): 629-634.

16. Koller M, Hesse P, Bona R, Kutschera C, Atlić A, Braunegg G. Potential of various archae-and eubacterial strains as industrial polyhydroxyalkanoate producers from whey. Macromol Biosci 2007; 7(2): 218-226.

17. Koller M, Atlić A, Gonzalez-Garcia Y, Kutschera C, Braunegg G. Polyhydroxyalkanoate (PHA) biosynthesis from whey lactose. Macromol Symp 2008; 272(1): 87-92).

18. Choi MH, Song JJ, Yoon SC. Biosynthesis of copolyesters by Hydrogenophaga pseudoflava from various lactones. Can J Microbiol 1995; 41(13): 60-67.

19. Yoon SC, Choi MH. Local sequence dependence of polyhydroxyalkanoic acid degradation in Hydrogenophaga pseudoflava. J Biol Chem 1999; 274(53): 37800-37808.

20. Koller M, Hesse P, Fasl H, Stelzer F, Braunegg G. Study on the effect of levulinic acid on whey-based biosynthesis of Poly(3-hydroxybutyrate-co-3-hydroxyvalerate) by Hydrogenophaga pseudoflava. Appl Food Biotechnol 2017; 4(2): 65-78.

21. Choi MH, Yoon SC, Lenz RW. Production of poly (3-hydroxybutyric acid-co-4-hydroxybutyric acid) and poly(4-hydroxybutyric acid) without subsequent degradation by Hydrogenophaga pseudoflava. Appl Environ Microbiol 1999; 65(4): 1570-1577.

22. Choi MH, Lee HJ, Rho JK, Yoon SC, Nam JD, Lim D, Lenz RW. Biosynthesis and local sequence specific degradation of poly(3-hydroxyvalerate-co-4-hydroxybutyrate) in Hydrogenophaga pseudoflava. Biomacromolecules 2003; 4(1): 38-45.

23. Brigham C, Kehail AA, Palmer JD. Ralstonia eutropha and the production of value added products: metabolic background of the wild-type strain and its role as a diverse, genetically-engineered biocatalyst organism. In: Koller M (Ed.): Recent Advances in Biotechnology Volume 1: Microbial Biopolyester Production, Performance and Processing: Microbiology, Feedstocks, and Metabolism. Potomac, Maryland, USA. Bentham Science Publishers Ltd. 2016. pp. 265-347.

24. Kaur G, Roy I. Strategies for large-scale production of polyhydroxyalkanoates. Chem Biochem Eng Q 2015; 29(2): 157-172.

25. Lillo JG, Rodriguez-Valera F. Effects of culture conditions on poly( $\beta$-hydroxybutyric acid) production by Haloferax mediterranei. Appl Environ Microbiol 1990; 56(8): 2517-2521. 
26. Page WJ, Cornish A. Growth of Azotobacter vinelandii UWD in fish peptone medium and simplified extraction of poly- $\beta$-hydroxybutyrate. Appl Environ Microbiol 1993; 59(12): 4236-4244.

27. Koller M, Bona R, Hermann C, Horvat P, Martinz J, Neto J, Pereira L, Varila P, Braunegg, G. Biotechnological production of poly(3-hydroxybutyrate) with Wautersia eutropha by application of green grass juice and silage juice as additional complex substrates. Biocat Biotrans 2005; 23(5): 329-337.

28. Davis R, Kataria R, Cerrone F, Woods T, Kenny S, O'Donovan A, et al Conversion of grass biomass into fermentable sugars and its utilization for medium chain length polyhydroxyalkanoate ( $\mathrm{mcl}-\mathrm{PHA})$ production by Pseudomonas strains. Bioresource Technol 2013; 150: 202-209.

29. Koller M, Sandholzer D, Salerno A, Braunegg G, Narodoslawsky M. Biopolymer from industrial residues: Life cycle assessment of poly(hydroxyalkanoates) from whey. Resour Conserv Recy 2013; 73: 64-71.

30. Obruca S, Benesova P, Oborna J, Marova I. Application of protease-hydrolyzed whey as a complex nitrogen source to increase poly(3-hydroxybutyrate) production from oils by Cupriavidus necator. Biotechnol Lett 2014; 36(4): 775-781.

31. Schmid M, Dallmann K, Bugnicourt E, Cordoni D, Wild F, Lazzeri A, Noller K. Properties of whey-protein-coated films and laminates as novel recyclable food packaging materials with excellent barrier properties. Int J Polym Sci 2012; 2012.

32. Cinelli P, Schmid M, Bugnicourt E, et al. Whey protein layer applied on biodegradable packaging film to improve barrier properties while maintaining biodegradability. Polym Degrad Stabil 2014; 108: 151-7.

33. Koller M, Marsalek L, Braunegg G. PHA Biopolyester Production from Surplus Whey: Microbiological and Engineering Aspects. In: Koller M (Ed.): Recent Advances in Biotechnology Volume 1: Microbial Biopolyester Production, Performance and Processing: Microbiology, Feedstocks, and Metabolism. Potomac, Maryland, USA. Bentham Science Publishers Ltd. 2016. pp. 100-172.

34. Koller M, Braunegg G. Advanced approaches to produce polyhydroxyalkanoate (PHA) biopolyesters in a sustainable and economic fashion. The EuroBiotech Journal 2018; 2(2): 89-103.

35. Koller M, Puppi D, Chiellini F, Braunegg G. Comparing chemical and enzymatic hydrolysis of whey lactose to generate feedstocks for haloarchaeal poly(3-hydroxybutyrate-co-3-hydroxyvalerate) biosynthesis. Int J Pharm Sci Res 2016; 3(1).

36. Braunegg G, Sonnleitner BY, Lafferty RM. A rapid gas chromatographic method for the determination of poly- $\beta$-hydroxybutyric acid in microbial biomass. Eur J Appl Microbiol Biotechnol 1978; 6(1): 29-37.

37. Daiber KH. Enzyme inhibition by polyphenols of sorghum grain and malt. J Sci Food Agric 1975; 26(9): 1399-1411.

38. Obruca S, Sedlacek P, Koller M, Kucera D, Pernicova I. Involvement of polyhydroxyalkanoates in stress resistance of microbial cells: Biotechnological consequences and applications. Biotechnol Adv 2018; 36(3): 856-870.

39. Novak $M$, Koller $M$, Braunegg $M$, Horvat P. Mathematical modelling as a tool for optimized PHA production. Chem Biochem Eng Q 2015; 29(2): 183-220.

40. Koller M, Vadlja D, Braunegg G, Atlić A, Horvat P. Formal-and high-structured kinetic process modelling and footprint area analysis of binary imaged cells: Tools to understand and optimize multistage-continuous PHA biosynthesis. The EuroBiotech Journal 2017; 1(3): 203-211.

41. Sindhu R, Silviya N, Binod P, Pandey A. Pentose-rich hydrolysate from acid pretreated rice straw as a carbon source for the production of poly-3-hydroxybutyrate. Biochem Eng J 2013; 78: 67-72.

42. Koller M, Bona R, Chiellini E, Fernandes EG, Horvat $\mathrm{P}$, Kutschera $C$, Hesse P, Braunegg G. Polyhydroxyalkanoate production from whey by Pseudomonas hydrogenovora. Bioresource Technol 2008; 99(11): 4854-4863.

43. Obruca S, Benesova P, Marsalek L, Marova I. Use of lignocellulosic materials for PHA production. Chem Biochem Eng Q 2015; 29(2): 135-144.

44. Lopes MSG, Gomez JGC, Taciro MK, Mendonça TT, Silva LF. Polyhydroxyalkanoate biosynthesis and simultaneous remotion of organic inhibitors from sugarcane bagasse hydrolysate by Burkholderia sp. J Ind Microbiol Biotechnol 2014; 41(9): 1353-1363.

45. Kucera D, Benesova P, Ladicky P, Pekar M, Sedlacek P, Obruca S. Production of polyhydroxyalkanoates using hydrolyzates of spruce sawdust: Comparison of hydrolyzates detoxification by application of overliming, active carbon, and lignite. Bioengineering 2017: 4(2): 53. 